\title{
Genotipagem de polimorfismos no gene prnp em ovinos da raça Santa Inês no Estado de São Paulo ${ }^{1}$
}

\author{
Caio R. Santos ${ }^{2}$, Enio Mori ${ }^{3}$, Diego A. Leão ${ }^{4}$ e Paulo C. Maiorka²
}

\begin{abstract}
Santos C.R., Mori E., Leão D.A. \& Maiorka P.C. 2012. [Genotyping of polymorphisms in the prnp gene in Santa Ines sheep in the State of São Paulo, Brazil.] Genotipagem de polimorfismos no gene prnp em ovinos Santa Inês no Estado de São Paulo. Pesquisa Veterinária Brasileira 32(3):221-226. Laboratório de Neuropatologia Experimental e Comparada, Departamento de Patologia, Faculdade de Medicina Veterinária e Zootecnia, Universidade de São Paulo, Av. Prof. Dr. Orlando Marques de Paiva 87, Cidade Universitária, São Paulo, SP 05508-270, Brazil. E-mail: caio-patologia@usp.br

Enzootic paraplexia or scrapie is a fatal neurodegenerative disease affecting mainly sheep and rarely goats. The disease is influenced by polymorphisms at codons 136, 154 and 171 of prnp gene that encodes the prion protein. The animals may be susceptible or resistant to the development of the disease according to the allelic sequences observed in these codons. In Brazil there were only cases of scrapie in imported animals, therefore the country is considered free of the disease. This study performed the genotyping of different polymorphisms associated to the development of scrapie. Then, based on these findings the animals were categorized in resistant and susceptible. A total of 118 samples were sequenced from the Santa Ines sheep raised on properties located in the State of Sao Paulo. From these samples, 6 alleles and 11 genotypes were identified (ARQ / ARQ, ARR / ARQ ARQ / AHQ, ARQ / VRQ AHQ / AHQ, ARR / ARR, ARR / AHQ, VRQ / VRQ, ARQ / TRQ, TRR / TRR, TRQ / TRQ), the genotype ARQ / ARQ presented a frequency of $56.7 \%$. It was also detected the presence of tyrosine at codon 136, which may be considered a rare observation, since there is no report regarding Santa Ines breeding presenting this polymorphism. These results showed the great genetic variability in Santa Ines in Sao Paulo and only 1,69\% of the genotypes observed are extremely resistant to scrapie. These data demonstrate that the Santa Ines sheep can be considered potentially susceptible to scrapie.
\end{abstract}

INDEX TERMS: Scrapie, enzootic paraplexia, genotyping of polymorphisms.

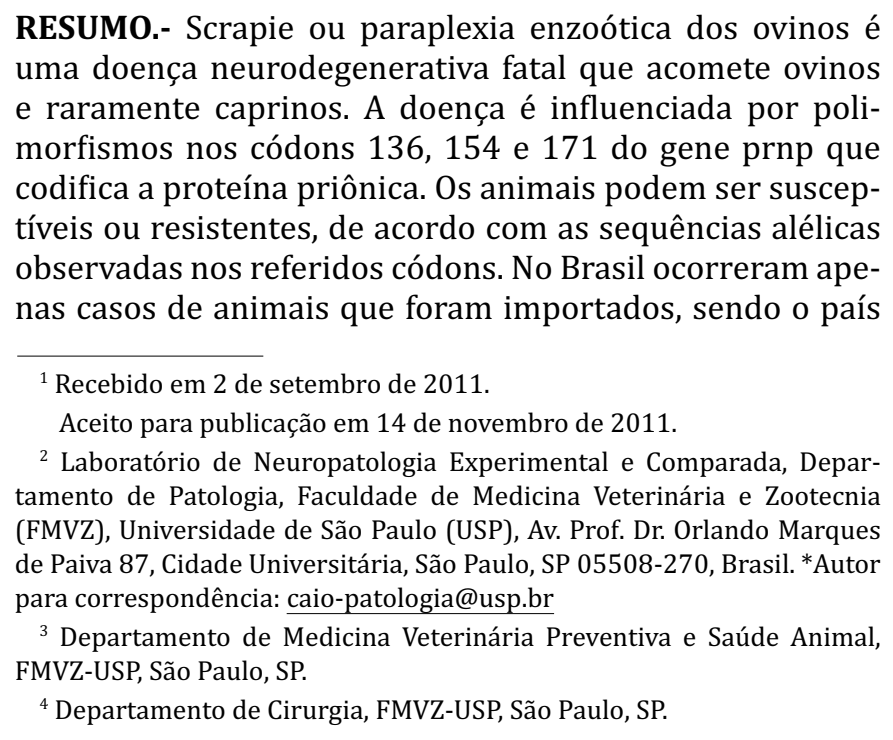

RESUMO.- Scrapie ou paraplexia enzoótica dos ovinos é uma doença neurodegenerativa fatal que acomete ovinos e raramente caprinos. A doença é influenciada por polimorfismos nos códons 136, 154 e 171 do gene prnp que codifica a proteína priônica. Os animais podem ser susceptíveis ou resistentes, de acordo com as sequências alélicas observadas nos referidos códons. No Brasil ocorreram apenas casos de animais que foram importados, sendo o país

\footnotetext{
${ }^{1}$ Recebido em 2 de setembro de 2011.

Aceito para publicação em 14 de novembro de 2011.

${ }^{2}$ Laboratório de Neuropatologia Experimental e Comparada, Depar(FMVZ), Universidade de São Paulo (USP), Av. Prof. Dr. Orlando Marques para correspondência: caio-patologia@usp.br

${ }^{3}$ Departamento de Medicina Veterinária Preventiva e Saúde Animal, FMVZ-USP, São Paulo, SP.

${ }^{4}$ Departamento de Cirurgia, FMVZ-USP, São Paulo, SP.
} tamento de Patologia, Faculdade de Medicina Veterinária e Zootecnia de Paiva 87, Cidade Universitária, São Paulo, SP 05508-270, Brasil. *Autor

considerado livre da doença. Neste trabalho foi realizada a genotipagem dos diferentes polimorfismos associados ao desenvolvimento do scrapie e a categorização em animais susceptíveis e resistentes. Foram sequenciadas 118 amostras provenientes de ovinos da raça Santa Inês criados em propriedades localizadas no Estado de São Paulo. Destas amostras foram identificados 6 alelos e 11 genótipos (ARQ/ ARQ, ARR/ARQ, ARQ/AHQ ARQ/VRQ, AHQ/AHQ ARR/ ARR, ARR/AHQ, VRQ/VRQ, ARQ/TRQ, TRR/TRR, TRQ/ TRQ), dentre os quais o genótipo ARQ/ARQ teve ocorrência de 56,7\%. Em nosso estudo foi detectada a presença da tirosina no códon 136, observação rara na medida em que não existem relatos nacionais e internacionais envolvendo a raça Santa Inês descrevendo este polimorfismo. Com os resultados obtidos, foi possível determinar a existência de grande variabilidade genética relacionada à raça Santa Inês no Estado de São Paulo. Apesar da variabilidade, apenas $1,69 \%$ dos genótipos observados mostraram-se extrema- 
mente resistentes ao scrapie. Estes dados demonstram que a raça nativa Santa Inês pode ser considerada potencialmente susceptível ao scrapie.

TERMOS DE INDEXAÇÃO: Scrapie, doenças em ovinos, genotipagem de polimorfismos, sequenciamento genômico.

\section{INTRODUÇÃO}

Scrapie ou paraplexia enzoótica dos ovinos é a mais antiga encefalopatia subaguda transmissível descrita na literatura, sendo que os primeiros relatos científicos foram produzidos ainda no século 18 (Roels et al. 2004). Esta doença é caracterizada por lesões neurodegenerativas e vacuolizações no sistema nervoso central (SNC). Clinicamente os animais acometidos apresentam alterações comportamentais como ataxia, descoordenação motora, paralisia motora e tremores (McGavin 2006). Além de alterações nervosas, os animais apresentam prurido intenso que os levam a esfregar-se contra tronco de árvores, troncos de contenção e cercas, alterações que deram origem ao termo "scrapie" que vem da expressão inglesa "to scrapie against something", que significa esfregar-se contra alguma coisa (Mapa 2008).

0 agente causador é chamado de príon $\left(\mathrm{PrP}^{\mathrm{SC}}\right)$, uma forma alterada da proteína priônica normal $\left(\operatorname{PrP}^{C}\right)$. A $\operatorname{PrP}^{C}$ esta presente na membrana celular de diversas células dos animais, principalmente no SNC. A infecção pelo $\mathrm{PrP}^{\mathrm{SC}}$ ocorre mais comumente por três formas: hereditariedade, consumo de alimentos oriundos de animais portadores da $\operatorname{PrP}^{\mathrm{sc}}$ ou por eventuais polimorfismos localizados no gene prnp (Cobb \& Surewicz 2009). O PrPsC uma vez presente no hospedeiro irá interagir com a $\mathrm{PrP}^{\mathrm{C}}$, e esta interação resultará em uma alteração da conformação terciária da proteína normal transformando-a em $\operatorname{PrP}^{\mathrm{sc}}$ (Luhken et al. 2004). Em casos de hereditariedade e polimorfismos o PRPN apresentará alterações na sequência de nucleotídeos na forma de polimorfismos de único nucleotídeo (SNPs) (Wang et al. 2008). Sabe-se que polimorfismos nos códons 136, 154 e 171 presentes no exon 3 do gene prnp têm relação com a resistência ao desenvolvimento do scrapie (Roels et al. 2004, Wang et al. 2008). Ao contrário da $\operatorname{PrP}^{\mathrm{C}}$, as $\operatorname{PrP}^{\mathrm{SC}}$ são resistentes a ação de proteases, com capacidade de formar grandes agregados insolúveis de proteína (Tzaban et al. 2002). Estes agregados proteicos ocorrem principalmente no SNC, acarretando desordens neurodegenerativas como vacuolização e perda neuronal severa (Deriziotis \& Tabrizi 2008).

De acordo com a susceptibilidade ao desenvolvimento de scrapie os animais podem ser classificados em altamente susceptíveis, susceptíveis ou resistentes (Dawson et al. 1998). Estas possibilidades dependem da combinação alélica dos códons 136, 154 e 171 do gene prnp (Roels et al. 2004). Os alelos do gene prnp codificadores para os aminoácidos Alanina (A) no códon 136, Arginina (R) no códon 154 e Arginina no códon 171 são denominados ARR. Os alelos do gene prnp codificadores para os aminoácidos Alanina (A) no códon 136, Histidina (H) no códon 154 e Glutamina (Q) no códon 171 são denominados AHQ. Os alelos do gene prnp codificadores para os aminoácidos Alanina (A) no códon 136, Arginina (R) no códon 154 e Glutamina no códon 171 são denominados ARQ. Os alelos do gene prnp codificadores para os aminoácidos Valina (V) no códon 136, Arginina (R) no códon 154 e Glutamina (Q) no códon 171 são denominados VRQ. Os alelos do gene prnp codificadores para os aminoácidos Alanina (A) no códon 136, Glutamina (R) no códon 154 e Histidina (H) no códon 171 são denominados (Luhken et al. 2004).

São considerados altamente susceptíveis ao scrapie, animais que apresentem no seu genótipo a combinação VRQ para o gene prnp, independentemente do outro alelo. São considerados como susceptíveis, ovinos que apresentem no seu genótipo a combinação alélica ARQ, AHQ, ou ARH para o gene prnp. São considerados resistentes ao desenvolvimento de scrapie os ovinos que apresentem no genótipo dois alelos ARR para o gene prnp (Wang et al. 2008).

No Brasil o primeiro relato de scrapie foi registrado em 1978, referindo-se a um ovino importado (Fernandes et al. 1978, Sotomaior et al. 2008). Os últimos relatos no Brasil aconteceram entre 2005 e 2010 (Wahid 2011) todos em animais importados. Perante o exposto, estudos genotípicos envolvendo raças nacionais são necessários para avaliar o grau de resistência e susceptibilidade do rebanho nacional, uma vez que o número de trabalhos publicados até o presente momento envolvendo raças nativas é muito pequeno.

O intuito deste estudo foi categorizar ovinos da raça Santa Inês criados no Estado de São Paulo em animais susceptíveis ou resistentes, por meio de genotipagem do gene prnp. Esta categorização irá corroborar com um melhor estudo e controle epidemiológico do scrapie, uma vez que conhecido o genótipo, pode-se evitar o cruzamento de animais com alelos VRQ, considerados extremamente susceptíveis ao desenvolvimento da doença.

\section{MATERIAL E MÉTODOS}

\section{Amostras}

Foram utilizadas 118 amostras de sangue de diferentes animais, todas coletadas por via intravenosa. Este procedimento foi realizado com tubos Vacutanier ${ }^{\circledR}$ contendo EDTA. As amostras de sangue foram aliquotadas em três partes iguais de $1,5 \mathrm{ml}$ cada, as quais após identificação foram conservadas a $-80^{\circ} \mathrm{C}$. Os animais pertencem a 4 propriedades em diferentes localidades do Estado de São Paulo. Essas propriedades foram nomeadas como (A) localizada na cidade de São Paulo, (B) localizada na cidade de São Paulo, (C) localizada na cidade de Rio Claro e (D) localizada na cidade de Sarapuí.

Todas as amostras coletadas pertencem a espécie Ovina (Ovis airies), raça Santa Inês e com idade variando de 8 meses a 4 anos e meio. 0 sistema de criação utilizado nas propriedades A e B são semi-intensivos, e nas propriedades C e D o sistema de criação é intensivo.

\section{Extração do DNA}

As extrações do DNA genômico foram realizadas a partir de sangue total. Para o procedimento foi adotado como método de extração o kit comercial Illustra ${ }^{\mathrm{TM}}$ Blood Genomic GE Healthcare ${ }^{\circledR}$. Após a extração, o DNA obtido foi aliquotado em três partes iguais e armazenado em freezer a $-80^{\circ} \mathrm{C}$. A integridade do DNA foi analisada por eletroforese em gel de agarose a $2 \%$, corado com Brometo de Etideo e analisado sob luz ultravioleta (UV) (Fig.1a). 


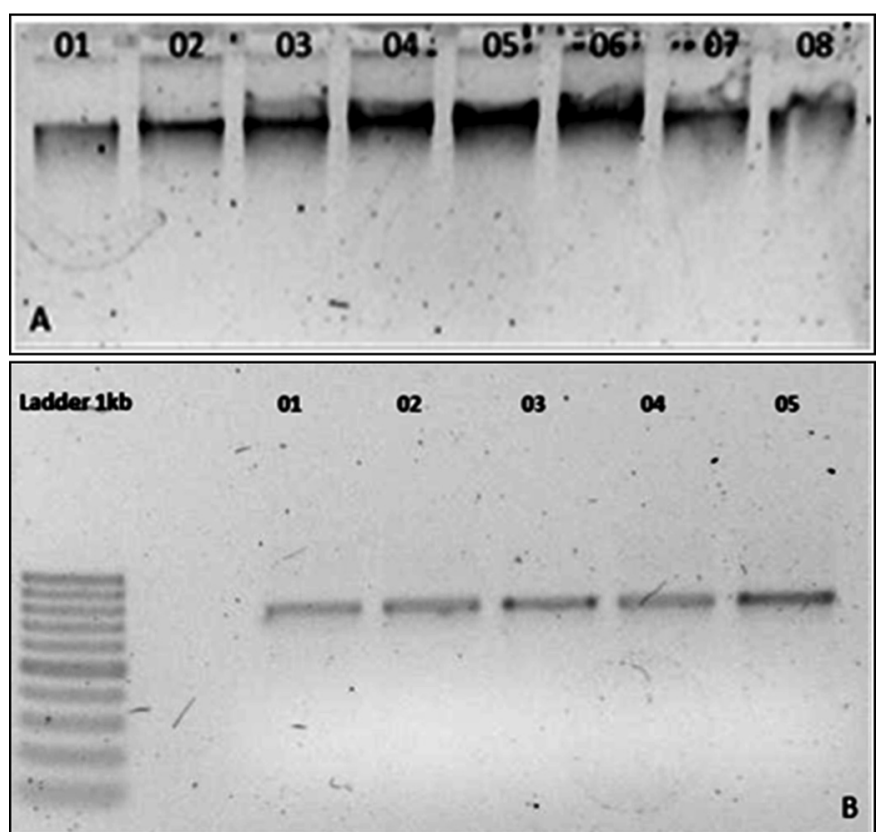

Fig.1. (A) Gel representativo para determinar a integridade do DNA antes da reação de PCR. (B) Gel representativo para determinar a eficiência da amplificação.

\section{Reação em Cadeia da Polimerase (PCR)}

As amostras genéticas obtidas foram amplificadas para detecção dos polimorfismos do gene prnp utilizando o kit AmpliTaq Gold (ABI). As reações foram submetidas a 40 ciclos de amplificação como descrito a seguir: $15 \mathrm{seg}$ a $95^{\circ} \mathrm{C}, 60 \mathrm{seg}$ a $60^{\circ} \mathrm{C}$. Os oligonucleotídeos iniciadores e reversos utilizados foram 5'-ATGGTGAAAAGCCACATAGGCAGT-3' e 5'-CTATCCTACTATGAGAAAAATGAG-3' respectivamente, os quais amplificaram um produto de $771 \mathrm{pb}$. A análise da amplificação foi por eletroforese em gel de agarose a $2 \%$, sendo que os géis foram corados por Brometo de Etideo e analisados sob luz ultravioleta (UV). As bandas obtidas após a amplificação eram únicas, com 771 pares de base. Para auxiliar na determinação do peso molecular das bandas foi utilizado o padrão de $1 \mathrm{~kb}$ de pares de bases (Plus Ladder- Ivitrogenß), (Fig.1b). 0 volume final da reação foi de $50 \mu$ l contendo 25 $\mu \mathrm{l}$ de PCR Master Mix (ABI), $5 \mu$ l de cada primer, DNA molde com concentração menor que $1 \mu \mathrm{M}$ e agua ultra pura.

\section{Sequenciamento}

Os produtos de PCR gerados foram purificados e sequenciados. Os oligonucleotídeos iniciadores e reversos utilizados foram 5'-GTAAGCCAAAAACCAACATGAAGC-3' 5'-TCGCTCCATTATCTTGATGTCAGTTT-3' respectivamente, ambos com a concentração de $5 \mu \mathrm{m}$. Para a reação de sequenciamento foi utilizado o equipamento 3730 DNA Analyzer (ABI). Os resultados obtidos foram analisados e comparados com a sequência de DNA depositada no GenBank com a identificação U67922.1., utilizando-se na ocasião como ferramenta o programa Blastn Suite (National Center for Biotechnology Information - NCBI) e pelo software Sequence Scanner v1.0 (ABI).

\section{Análise Genética e categorização}

Os resultados foram analisados e tabulados, e os animais categorizados quanto ao grau de resistência e susceptibilidade ao desenvolvimento de scrapie, de acordo com os critérios estabelecidos pelo genótipo apresentado. A classificação foi baseada na frequência alélica dos códons 136, 154 e 171, obtidas na genotipagem do gene prnp. Os genótipos encontrados neste estudo fo- ram classificados usando-se critérios estabelecidos por (Dawson et al., 1998). As possíveis combinações alélicas foram dividas em cinco grupos (R1-R5), sendo que a combinação alélica mais resistente se enquadra no Grupo R1 enquanto a combinação alélica mais susceptível se enquadra no Grupo R5 (Quadro 1).

\section{Quadro 1. Distribuição dos diferentes genótipos encontrados} no gene prnp com a respectiva classificação, adaptado de (Roels et al., 2004)

\begin{tabular}{ll}
\hline \multicolumn{1}{c}{ Grupo } & \multicolumn{1}{c}{ Genótipos } \\
\hline R1- Extremamente Resistente & ARR/ARR \\
R2 - Resistente & ARR/AHQ ARR/ARH ARR/ARQ \\
R3 - Leve Resistência & ARQ/ARQ ARQ/ARH ARQ/AHQ AHQ/ \\
& AHQ ARH/ARH AHQ/ARH \\
R4 - Susceptível & ARR/VRQ \\
R5 - Altamente Susceptível & VRQ/VRQ ARQ/VRQ ARH/VRQ AHQ/VRQ
\end{tabular}

\section{Propriedade A}

\section{RESULTADOS}

Nas 17 reações de sequenciamento referentes à Propriedade A o genótipo ARQ/ARQ se mostrou presente em sete amostras $(41,1 \%)$, seguido dos genótipos ARR/ ARQ presentes em quatro (23,5\%), o AHQ/AHQ em duas $(11,7 \%)$, o ARQ/AHQ em duas $(11,7 \%)$ e o ARQ/VRQ em duas $(11,7 \%)$. Estes resultados mostram que $23,5 \%$ dos animais desta propriedade pertencem ao grupo R2, considerados resistentes, $64,7 \%$ pertencem ao grupo R3, considerados animais com baixa resistência e 11,7\% pertencem ao grupo R5 representado por animais altamente susceptíveis (Fig.2a).

\section{Propriedade B}

Na propriedade $B$ foram sequenciadas 10 amostras. Entre as amostras analisadas o genótipo ARQ/ARQ esteve presente em sete amostras (70\%), o genótipo ARR/ARQ presente em duas (20\%) e ARQ/AHQ em uma (10\%). Estes resultados indicam que $20 \%$ dos animais desta propriedade pertencem ao grupo $\mathrm{R} 2$, considerados resistentes e a maioria, 80\%, constituída por animais com baixa resistência, que pertencem ao grupo R3 (Fig.2b).

\section{Propriedade C}

Nas amostras referentes à Propriedade $\mathrm{C}$ foram realizadas 41 reações de sequenciamento. 0 genótipo ARQ/ARQ esteve presente em 29 amostras (70,7\%), seguido do genótipo ARR/ARQ presente em duas $(4,8 \%)$ e do ARR/ARR em duas $(4,8 \%)$. Já os genótipos ARQ/AHQ AHQ/AHQ ARQ/VRQ e VRQ/VRQ estavam presentes em uma amostra cada um $(2,4 \%$ cada). Em quatro amostras foi possível verificar a genotipagem de um polimorfismo raro, a presença da Tirosina no códon 136, correspondendo uma amostra TRR/TRR (2,4\%), uma amostra TRQ/TRQ (2,4\%), e duas amostras ARQ/TRQ (4,8\%). Estes resultados mostram que $4,9 \%$ dos animais desta propriedade pertencem ao grupo R1, considerados extremamente resistentes e $4,9 \%$ pertencem ao grupo R2 representado por animais resistentes. Já $75,5 \%$ pertencem ao grupo R3, composto por animais com baixa resistência e $4,9 \%$ do grupo R5, composto por animais altamente susceptíveis. Em 9,8\% das amostras analisadas não foi possível determinar a categorização, pois se tratavam-se de genótipos raros (Fig.2c). 

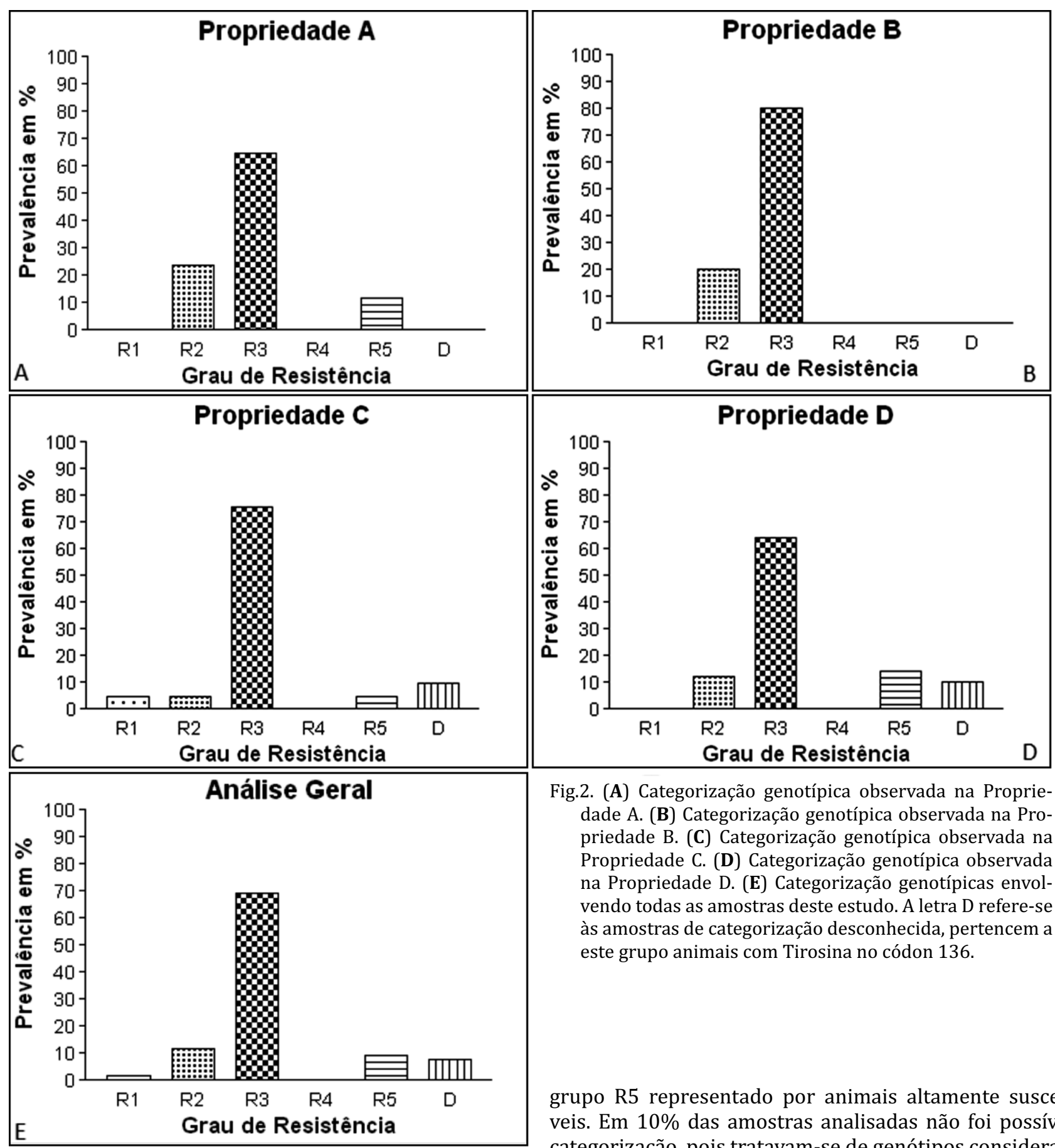

Fig.2. (A) Categorização genotípica observada na Propriedade A. (B) Categorização genotípica observada na Propriedade B. (C) Categorização genotípica observada na Propriedade C. (D) Categorização genotípica observada na Propriedade D. (E) Categorização genotípicas envolvendo todas as amostras deste estudo. A letra D refere-se às amostras de categorização desconhecida, pertencem a este grupo animais com Tirosina no códon 136.

\section{Propriedade D}

Na Propriedade D foram sequenciadas 50 amostras. 0 genótipo ARQ/ARQ estava presente em 24 amostras (48\%), os genótipos ARQ/VRQ em sete (14\%), e o ARQ/AHQ também sete (14\%). O ARR/ARQ estava em quatro amostras (8\%), o ARR/AHQ em duas (4\%), e o AHQ/AHQ em uma (2\%). A tirosina no códon 136 também pôde ser observada nesta propriedade, sendo que o genótipo ARQ/TRQ foi detectado em cinco amostras (10\%). Estes resultados indicam que $12 \%$ dos animais desta propriedade pertencem ao grupo R2, considerados resistentes, $64 \%$ são do grupo R3, considerados animais com baixa resistência e $14 \%$ ao

grupo R5 representado por animais altamente susceptíveis. Em $10 \%$ das amostras analisadas não foi possível à categorização, pois tratavam-se de genótipos considerados raros (Fig.2d)

\section{Análise geral}

Das 118 amostras sequenciadas, o genótipo ARQ/ARQ esteve presente em sessenta e sete amostras $(56,7 \%)$, seguido dos genótipos ARR/ARQ em doze $(10,1 \%)$, ARQ/ AHQ em onze (9,3\%), ARQ/VRQ em dez (8,4\%), ARQ/TRQ em cinco (4,2\%), AHQ/AHQ em quatro (3,3\%), ARR/ARR e ARR/AHQ em duas amostras cada (1,7\%), VRQ/VRQ TRR/ TRR e TRQ/TRQ em uma amostra cada (0,8\%). Portanto $78,7 \%$ dos animais estudados são considerados susceptíveis ao scrapie, sendo $69,4 \%$ pertencentes ao grupo R3 e 9,3\% ao grupo R5 (Fig.2e). 


\section{DISCUSSÃO E CONCLUSÕES}

De 118 amostras genotipadas, 6 diferentes alelos foram detectados, formando 11 genótipos. Outros estudos envolvendo a raça Santa Inês, Lima et al. (2007) mostraram que em 29 amostras genotipadas foram encontrados 9 alelos e 13 genótipos. Os resultados semelhantes demonstram que a raça Santa Inês possui grande variabilidade genética. Em contrapartida, estudos envolvendo a raça nativa Morada Nova, indicam que a raça apresenta baixa variabilidade, Pacheco et al. (2007) demonstraram que de 72 amostras genotipadas foram encontrados apenas 3 alelos e 4 genótipos, sendo na ocasião utilizadas amostras provenientes de rebanhos criados no Estado do Ceará.

Dentro da classificação proposta por Dawson et al. (1998), as amostras em que o alelo VRQ esta presente, enquadram-se no grupo R5. Foram detectados dois genótipos com a presença do alelo VRQ ARQ/VRQ, presente em $8,7 \%$ das amostras, e VRQ/VRQ presente em $0,84 \%$ das amostras. Portanto, de acordo com este critério 9,3\% dos animais analisados são altamente susceptíveis ao desenvolvimento da doença. Sotomaior et al. (2008) e Lima et al. (2007), analisando animais da raça Santa Inês, não detectaram o genótipo VRQ/VRQ, considerado o mais susceptivel. Este é o primeiro relato do genótipo VRQ/VRQ em ovinos da raça Santa Inês, mesmo que em baixa frequência, sendo importante ressaltar que esta combinação genotípica é a mais susceptível ao scrapie. Neste caso recomenda-se preocupação com o manejo e alimentação destes animais, afim de evitar eventuais contatos com o agente infeccioso.

Com presença de $56,7 \%$ das amostras analisadas, o genótipo ARQ/ARQ foi o mais freqüente. Levando em consideração que essa combinação não é considerada resistente, fica claro que mais da metade do rebanho ovino analisado tem susceptibilidade ao desenvolvimento da doença. De maneira semelhante Sotomaior et al. (2008) e Lima et al. (2007) em seus estudos verificaram a predominância do genótipo ARQ/ARQ nos animais analisados, sendo que nestas ocasiões foram analisadas amostras de animais criados no Brasil. Os resultados semelhantes demonstram que a raça nativa Santa Inês é potencialmente susceptivel ao scrapie. No entanto, nenhum relato da doença na raça foi reportado até o presente momento, ou seja os relatos de scrapie no Brasil não relacionam a raça Santa Inês.

O genótipo considerado extremamente resistente ARR/ ARR, foi detectado em apenas $0,84 \%$ das amostras analisadas. Em outros estudos realizados envolvendo a raça nacional Santa Inês não foi detectado este genótipo (Lima et al. 2007, Sotomaior et al. 2008). A baixa frequência do alelo ARR no rebanho nacional reforça a susceptibilidade da raça Santa Inês em relação ao scrapie.

Em nove amostras pode ser observada a presença da Tirosina no códon 136, resultando nos genótipos: A/T e $\mathrm{T} / \mathrm{T}$. Até o presente momento estes polimorfismos só foram descritos em publicações internacionais e são considerados como observações raras (Billinis et al. 2004, Guan et al. 2011). Assim, este é o primeiro relato nacional e o único relato envolvendo a raça Santa Inês. 0 efeito na susceptibilidade ou resistência nos animais portadores da homozigose T/T no códon 136 ainda não está totalmente elucidado
(Guan et al. 2011), já a heterozigose A/T não altera a susceptibilidade a doença (Billinis et al. 2004).

De acordo com a classificação proposta por Dawson et al. (1998) é possivel determinar que apenas 1,69\% dos animais analisados pertencem ao Grupo R1, os quais são extremamente resistentes ao scrapie. Dentro do grupo R2, representgado por animais resistentes, puderam ser alocados $11,8 \%$ dos animais analisados. Animais considerados com baixa resistência fazem parte do Grupo R3, sendo que neste estudo, 69,4\% dos animais analisados pertencem a este grupo, fato este que permite considerar que grande parte da população analisada possui susceptibilidade ao desenvolvimento da doença. Não foram observados animais pertencentes ao Grupo R4. 0 Grupo R5 é representado por animais extremamente susceptíveis ao desenvolvimento da doença, sendo que 9,3\% dos animais analisados fazem parte deste grupo. Em 7,6\% dos animais analisados, não foi possivel determinar o grau de resistência, pois apresentaram polimorfismos raros, os quais ainda não foram categorizados.

Diversos trabalhos internacionais foram realizados por outros grupos e mostraram resultados variados (Sipos et al. 2002, Acin et al. 2004, Gama et al. 2006, Molina et al. 2006) descreveram que o genótipo ARQ/ARQ é o mais frequente nas populações analisadas, resultado semelhantes ao encontrado neste trabalho. Em contrapartida Dawson et al. (1998) e Roels et al. (2004) descreveram que a maioria dos animais analisados em seus trabalhos é resistente ou extremamente resistente ao desenvolvimento da doença.

Com os dados obtidos neste trabalho e com base em outros estudos nacionais, pode-se concluir que a raça Santa Inês é potencialmente susceptível ao desenvolvimento do scrapie. Apesar da susceptibilidade relacionada à raça, os relatos nacionais da doença somente se reportaram a animais da raça Suffolk e Hampshire Down (Lima et al. 2007, Sotomaior et al. 2008). Importante finalmente ressaltar que os cruzamentos de animais Santa Inês com Hampshire Down estão se tornando cada vez mais frequentes (Lima et al. 2007), o que torna necessário a realização de estudos de frequência alélica e genotípica dos animais envolvidos nestes cruzamentos.

Agradecimentos.- Ao Prof. Dr. Paulo Eduardo Brandão pela disponibilização do Laboratório. Ao Conselho Nacional de Desenvolvimento Científico e Tecnológico (CNPq) pelo financiamento do Projeto 578158/2008-6 (Edital MAPA 64/2008).

\section{REFERÊNCIAS}

Acin C., Martin-Burriel I., Goldmann W., Lyahyai J., Monzon M., Bolea R., Smith A., Rodellar C., Badiola J.J. \& Zaragoza P. 2004. Prion protein gene polymorphisms in healthy and scrapie-affected Spanish sheep. J. Gen. Virol. 85:2103-2110.

Billinis C., Psychas V., Leontides L., Spyrou V., Argyroudis S., Vlemmas I., Leontides S., Sklaviadis T. \& Papadopoulos 0. 2004. Prion protein gene polymorphisms in healthy and scrapie-affected sheep in Greece. J. Gen. Virol. 85:547-554.

Cobb N.J. \& Surewicz W.K. 2009. Prion diseases and their biochemical mechanisms. Biochemistry 48:2574-2585.

Dawson M., Hoinville L.J., Hosie B.D. \& Hunter N. 1998. Guidance on the use of PrP genotyping as an aid to the control of clinical scrapie. Vet. Rec. 142:623-625. 
Deriziotis P. \& Tabrizi S.J. 2008. Prions and the proteasome. Biochim Biophys Acta 1782:713-722.

Fernandes R.E., Real C.M. \& Fernandes J.C.T. 1978. "Scrapie" em ovinos no Rio Grande do Sul. Arqs Fac. Vet. UFRGS 6:139-143.

Gama L.T., Carolino M.I., Santos-Silva M.F., Pimenta J.A. \& Costa M.S. 2006. Prion protein genetic polymorphisms and breeding strategies in Portuguese breeds of sheep. Livest. Sci. 99:175-184.

Guan F., Pan L., Li J., Tang H., Zhu C. \& Shi G. 2011. Polymorphisms of the prion protein gene and their effects on litter size and risk evaluation for scrapie in Chinese Hu sheep. Virus Genes 43:147-152.

Lima A.C., Bossers A., Souza C.E., Oliveira S.M. \& Oliveira D.M. 2007. PrP genotypes in a pedigree flock of Santa Ines sheep. Vet. Rec. 160:336337.

Luhken G., Buschmann A., Groschup M.H. \& Erhardt G. 2004. Prion protein allele $A(136) H(154) Q(171)$ is associated with high susceptibility to scrapie in purebred and crossbred German Merinoland sheep. Archs Virol. 149:1571-1580.

Mapa. 2008. Programa Nacional de Controle da Raiva dos Herbívoros e Outras Encefalopatias. In: Ministério da Agricultura, Pecuária e Abastecimento (Ed.), Sanidade Animal, Brasilia, BR (http://www.agricultura. gov.br/animal/sanidade-animal).

Molina A., Juarez M. \& Rodero A. 2006. Merino sheep breed's genetic resistance to Scrapie: Genetic structure and comparison of five eradication strategies. Prev. Vet. Med. 75:239-250.

Pacheco A.C.L., Oliveira S.M.P., Gouveia J.J.S., Diniz M.C., Vasconcelos E.J.R.,
Viana D.A., Rosinha G.M.S., Maggioni R., Costa B. \& Oliveira D.M. 2007. Analysis of prion protein gene (PRNP) polymorphisms in healthy Morada Nova sheep reavels the presence of genotypes susceptible to scrapie. Ciênc. Anim. 17:27-36.

Roels S., Renard C., De Bosschere H., Geeroms R., Van Poucke M., Peelman L. \& Vanopdenbosch E. 2004. Detection of polymorphisms in the prion protein gene in the Belgian sheep population: some preliminary data. Vet. Quart. 26:3-11.

Sipos W., Kraus M., Schmoll F., Achmann R. \& Baumgartner W. 2002. PrP genotyping of Austrian sheep breeds. J. Vet. Med. A 49:415-418.

Sotomaior C.S., Sotomaior V.S., Madeira H.M. \& Thomaz-Soccol V. 2008. Prion protein gene polymorphisms in sheep in the state of Parana, Brazil. Anim. Genet. 39:659-661.

Tzaban S., Friedlander G., Schonberger O., Horonchik L., Yedidia Y., Shaked G., Gabizon R. \& Taraboulos A. 2002. Protease-sensitive scrapie prion protein in aggregates of heterogeneous sizes. Biochemistry 41:1286812875.

Wahid 2011. Contry Informations, Diseases Timelines. In: World Organisation of Animal Health (Ed.), World Animal Health Information Database (WAHID), Paris (http://web.oie.int/wahis/public.php?page=home).

Wang Y., Qin Z., Qiao J. \& Zhao D. 2008. Polymorphisms of the prion protein gene in sheep of Inner Mongolia, China. Virus Genes 37:128-130.

Zachary J.F. 2006. Nervous System, p.899-900. In: McGavin M.D. \& Zachary J.F. (Eds), Pathologic Basis of Veterinary Disease. $4^{\text {th }}$ ed. Mosby Elsevier, St Louis. 